Nana Sugimoto • Yoji Fukuda • Fumiko Saito-Ohara

Ryuichi Kamiyama - Akira Nakagawara • Naomi Mukae

Shigekazu Nagata · Johji Inazawa

\title{
The human caspase-activated DNase gene (hCAD): genomic structure, exonic single-nucleotide polymorphisms, and a highly polymorphic dinucleotide repeat at the hCAD locus
}

Received: July 30, 1999 / Accepted: August 14, 1999

\begin{abstract}
Caspase-activated DNase (CAD) cleaves chromosomal DNA during apoptosis. We determined its genomic structure and identified single-nucleotide polymorphisms (SNPs) within exons 5 and 7, as well as a highly polymorphic dinucleotide repeat of $(\mathrm{CT}) \mathrm{m}(\mathrm{CA}) \mathrm{n}$ within the $5^{\prime}$ region of the human CAD gene $(h C A D)$. The genomic structure of $h C A D$ presented here, together with information concerning SNPs within the gene, as well as a highly polymorphic (CT)m(CA)n repeat fragment at the $h C A D$ locus, may assist in the construction of genetic maps for exploring gene(s) that play pivotal roles in carcinogenesis.
\end{abstract}

Key words CAD (caspase-activated-DNase) · Dinucleotide repeat $\cdot$ SNPs

\section{Introduction}

Caspase-activated DNase (CAD) cleaves chromosomal DNA during apoptosis (Enari et al. 1998). Recently the human CAD gene $(h C A D)$ was isolated and localized at chromosome 1p36.3 (Mukae et al. 1998), a T-band region rich in GC nucleotides that contains a number of important housekeeping genes (Gregory et al. 1998). Chromosome 1 p36 is frequently involved in hemizygous deletions in several types of neoplasms, in particular in neuroblastoma,

N. Sugimoto $\cdot$ Y. Fukuda $\cdot$ F. Saito-Ohara $\cdot$ J. Inazawa $(\bowtie)$ Department of Molecular Cytogenetics, Division of Genetics, Medical Research Institute, Tokyo Medical and Dental University, 1-5-45 Yushima, Bunkyo-ku, Tokyo 113-8510, Japan

Tel. +81-3-5803-5820; Fax +81-3-5803-0244

e-mail: johinaz.cgen@mri.tmd.ac.jp

N. Sugimoto $\cdot$ R. Kamiyama

School of Allied Health Science, Faculty of Medicine, Tokyo

Medical and Dental University, Tokyo, Japan

A. Nakagawara

Division of Biochemistry, Chiba Cancer Center, Chiba, Japan

N. Mukae $\cdot$ S. Nagata

Department of Genetics, Osaka University Medical School, Suita, Japan indicating the presence of one or more tumor suppressor genes in the region (White et al. 1995). Since $h C A D$ acts as a key enzyme for the cleavage of DNA during apoptotic processes, it is a likely candidate for one of these tumor suppressors, because its inactivation may cause failure of cells to undergo apoptotic DNA degradation (Sakahira et al. 1998). As a step toward exploring somatic mutations of the $h C A D$ in various types of malignant tumors, we determined its genomic structure and identified single-nucleotide polymorphisms (SNPs) within two exons, as well as a highly polymorphic dinucleotide repeat at the $h C A D$ locus.

\section{Results and discussion}

We used a full-length cDNA clone $(4.2 \mathrm{~kb})$, designated pKT-hCAD (Mukae et al. 1998), to screen a cosmid library prepared from human peripheral lymphocytes. Two cosmids containing genomic fragments of the $h C A D$ were isolated. Hybridization of these cosmids with a $(\mathrm{GT})_{10}$ probe on Southern blots, after digestion by RsaI, detected a CA-repeat in one of the fragments. The subcloned fragment was sequenced, to reveal a $(\mathrm{CT}) \mathrm{m}(\mathrm{CA}) \mathrm{n}$ microsatellite within the $5^{\prime}$ region of $h C A D$.

The polymerase chain reaction (PCR) primers designed to flank this repeat sequence for the analysis of polymorphism were: forward, 5'-CAAGCTAACTCAGTTGCATG; reverse, 5'-GCATGGACTGTGTCCTTGAC. PCR experiments were performed in volumes of $10 \mu$ l containing 10 ng genomic DNA, 0.25 units of EX-Taq DNA polymerase (Takara, Tokyo, Japan), $1 \times$ PCR buffer $(67 \mathrm{mM}$ Tris $[\mathrm{pH} 8.8], \quad 16.6 \mathrm{mM} \quad \mathrm{NH}_{2} \mathrm{SO}_{4}, 6.7 \mu \mathrm{M}$ ethylenediaminetetraacetic acid (EDTA), $10 \mathrm{mM} \quad \beta$-mercaptoethanol), $250 \mu \mathrm{M}$ dNTPs, and 1 pmol each of $\alpha\left[{ }^{32} \mathrm{P}\right]$ end-labeled forward primer and non-labeled reverse primer. Cycle conditions were $94^{\circ} \mathrm{C}$ for $2 \mathrm{~min}$, then 35 cycles of $94^{\circ} \mathrm{C}$ for $30 \mathrm{~s}$, $62^{\circ} \mathrm{C}$ for $30 \mathrm{~s}$, and $72^{\circ} \mathrm{C}$ for $30 \mathrm{~s}$, with final extension for $5 \mathrm{~min}$ at $72^{\circ} \mathrm{C}$. The PCR products were electrophoresed in 0.3$\mathrm{mm}$-thick denaturing $5 \%$ polyacrylamide gels containing $30 \%$ formamide and $7.7 \mathrm{M}$ urea, at $2,200 \mathrm{~V}$ for $2-4 \mathrm{~h}$. The 
gels were blotted onto filter papers, which were dried at $80^{\circ} \mathrm{C}$ and autoradiographed. Allelic status at this microsatellite marker was examined in 43 unrelated Japanese individuals, of whom 34 (79\%) showed heterozygosity, indicating that the frequency of heterozygosity at this locus was more than 0.79 .

Next we determined the exon-intron boundary sequences of $h C A D$, using the oligonucleotide primers originally employed for sequencing the cDNA (Mukae et al. 1998) to amplify introns. The PCR primer-pairs were designed to flank cDNA fragments 200-300 bp long that overlapped at the ends, to ensure that the entire gene was screened. Both cosmids containing genomic fragments of $h C A D$ were amplified by standard PCR protocols, and sequenced. A gap between them was filled by means of "long PCR", using $0.2 \mathrm{mM}$ of each primer and $100 \mathrm{ng}$ of total genomic DNA. Comparison of the published cDNA sequence of $h C A D$ (Mukae et al. 1998; GeneBank accession no. AB013918) with the genomic sequences indicated that the $h C A D$ consists of seven exons, and that all sequences at exon-intron boundaries conformed to the AG-GT consensus sequence, except for the intron 3/exon 4 boundary (Table 1). This structure is similar to that of murine $C A D$ (Kawane et al. 1999).

We used the PCR-single-strand conformation polymorphism (SSCP) technique with 92 chromosomes of unrelated Japanese individuals to ascertain whether polymorphic sites were present within the coding region of $h C A D$. The coding sequence was divided into nine parts; primers for amplify- ing each segment (Table 2) were designed so that an end portion of each amplified fragment overlapped the $5^{\prime}$ end of the next one. Ten-nanogram aliquots of genomic DNA from 46 unrelated Japanese individuals were amplified by each pair of primers under the PCR conditions described above. Variant bands were detected by SSCP in exons 5 and 7 , and the sequences of the corresponding PCR products were determined (Fig. 1A). To examine for polymorphism in exons 5 and 7, we carried out PCR experiments, using 61 normal DNA samples in volumes of $20 \mu$ l containing $20 \mathrm{ng}$ genomic DNA, $67 \mathrm{mM}$ Tris-Hcl $(\mathrm{pH} \quad 8.4), \quad 17 \mathrm{mM}$ $\left(\mathrm{NH}_{4}\right)_{2} \mathrm{SO}_{4}, \quad 24 \mathrm{mM} \quad \mathrm{MgCl}_{2}, \quad 0.07 \%$ 2-mercaptoethanol, $6.7 \mu \mathrm{M}$ EDTA ( $\mathrm{pH} 8.8), 250 \mu \mathrm{M}$ of each dNTP, $10 \mathrm{pmol}$ of each primer (ex5F and ex5R or ex7-2F and ex7-2R), and 0.5 units of Taq polymerase. Cycle conditions were as described above. Each of the PCR products revealed a singlenucleotide polymorphism: in exon 5, a G-to-A transversion at the second nucleotide of codon 196 created a restriction site of AluI and changed the amino acid from Arg to Lys; and an A-to-G transversion at the third nucleotide of codon 318 in exon 7 created an $A v a \mathrm{I}$ site but did not result in an amino-acid substitution (Fig. 1B). To clearly show fragments digested with AluI, the PCR products (200-bp-long) containing exon 5 were amplified using primers of ex $5 \mathrm{~F}^{\prime}$ : 5'-GGAGTGAGATGGATCGAGAG and ex5R': 5'CTCCTCTGTCGAAGTAGCTG. Three fragments (99-, 84-, and 17-bp) were generated from the A1 allele and four fragments (84-, 73-, 26-, and 17-bp) from the A2 allele (Arg196Lys), along with an additional AluI site. The PCR

Table 1. Exon-intron boundary sequences of the $h C A D$ coding region

\begin{tabular}{lcclll}
\hline Exon number & Exon length $(\mathrm{bp})$ & cDNA position & Splice acceptor & Splice donor & Intron number \\
\hline 1 & 114 & $1-114$ & & CCGCTTCCAG gtgccegctg & 1 \\
2 & 127 & $115-241$ & gtccetgcag CTCCCTGAGC & TGGCAGGGCT gtgagtggca & 2 \\
3 & 189 & $242-430$ & ttggtggcag ATGTGAGCGA & TGGTTGAAG gtgcgtgggg & 3 \\
4 & 80 & $431-510$ & gtttccttg GCTTGGAGTC & CCTGAGGGAG gtgagcctga & 4 \\
5 & 171 & $511-681$ & gttcctccag GTGAGCTCCT & CTCCTGCCAG gtgagctgtg & 5 \\
6 & 101 & $682-782$ & tggccccag GGTCCCTTTG & TGGATCACAT gtaagctcac & 6 \\
7 & 235 & $783-1,017$ & tacttgcag AATAGAAAAG & & \\
\hline
\end{tabular}

Table 2. Primer sequences for amplifying $h C A D$ coding region

\begin{tabular}{|c|c|c|}
\hline Name of primer & Nucleotide sequences & Product size (bp) \\
\hline $\operatorname{ex} 1 \mathrm{~F}$ & 5'-AGAGGGCTTGAGGACATCTG-3' & 196 \\
\hline ex1R & 5'-АССТССТАТТСТССССАСАС-3' & \\
\hline $\mathrm{ex} 2 \mathrm{~F}$ & 5'-ТCCTCCTCCTGTTGCTTCTC-3' & 179 \\
\hline ex2R & 5'-CCAAAGTCCTTGCCACTCAC-3' & \\
\hline ex3-1F & 5'-GTTTGTCCCATTGGTGGCAG-3' & 157 \\
\hline ex3-1R & 5'-GACGTTGTGCAGGAGGTCAG-3' & \\
\hline ex3-2F & 5'-CACAGAGGCAGAGGCAGAGGCTGCTG-3' & 144 \\
\hline ex3-2R & 5'-CCTCAGACTCCAAAGAAGCC-3' & \\
\hline ex4F & 5'-GTGGACTTGGGGGTCTTCTC-3' & 141 \\
\hline ex4R & 5'-AGCATACCCGGTCTTCACTC-3' & \\
\hline ex5F & 5'-CCGACGTTCCTTGGTTCCTC-3' & 216 \\
\hline $\operatorname{ex} 5 \mathrm{R}$ & 5'-GGATAAAGGGCACACAGCTC-3' & \\
\hline ex6F & 5'-TCTGGCCTTCCCTCATTGTC-3' & 161 \\
\hline ex6R & 5'-GGTCTGAACCTCGCTCTGTG-3' & \\
\hline ex7-1F & 5'-TGTGACCACAGAAAATGATGTC-3' & 181 \\
\hline ex7-1R & 5'-GGGGTTTGTAGATTCTGCTC-3' & \\
\hline ex7-2F & 5'-CACCCACAAGCTCAACTGTG-3' & 145 \\
\hline ex7-2R & 5'-GTTAAAATGATGCCCACGTC-3' & \\
\hline
\end{tabular}


A

ex5

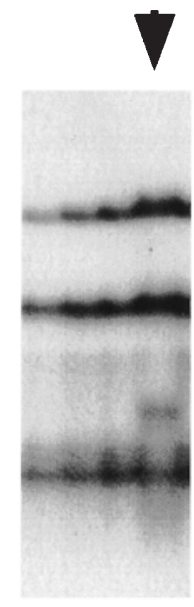

ex7

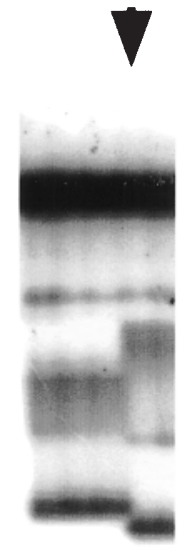

587(G $\rightarrow$ A) Arg196 $\rightarrow$ Lys
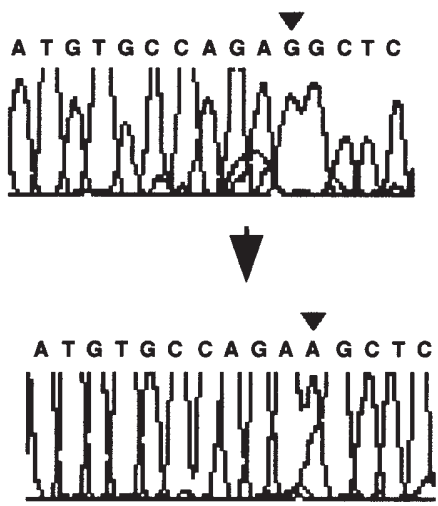

954
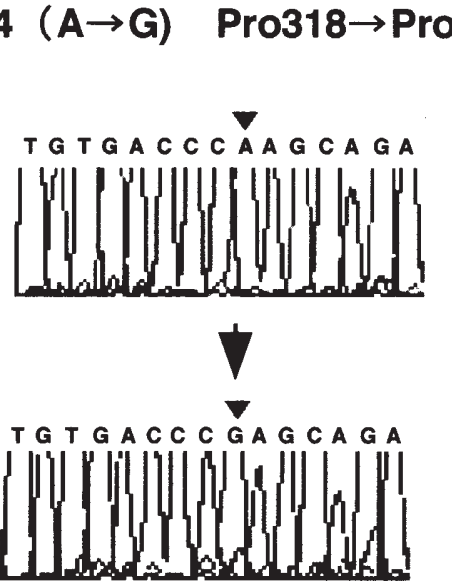

B

ex5

587

$A G G \rightarrow A A G$

Arg $\rightarrow$ Lys

$M \quad-1--1-+1+-1+-1+$

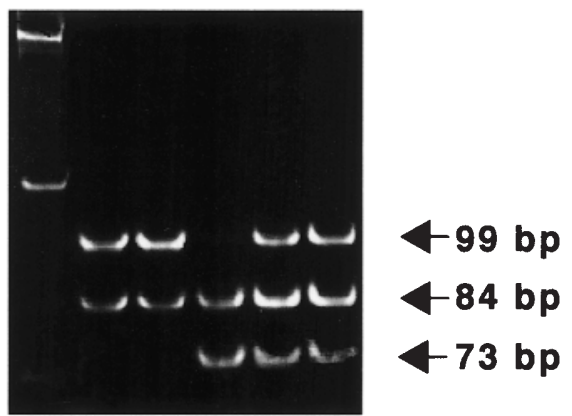

954

ex7

CCA $\rightarrow$ CCG

Pro $\rightarrow$ Pro

$M+/+-/--1--1+-/+$

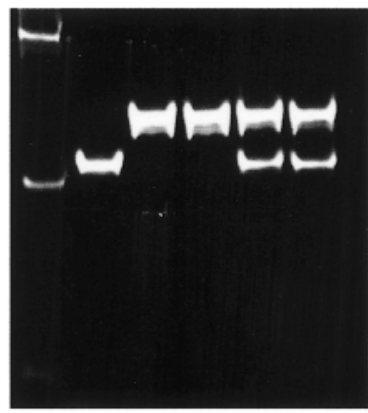

145 bp

123 bp
Fig. 1. A Single-strand conformation polymorphism (left panels) and sequence analysis of exons 5 and 7 of the $h C A D$. Arrows indicate variant band patterns. In exon 5 , a G-to-A transversion was detected at the second nucleotide of codon 196, resulting in an amino acid change of Arg $\rightarrow$ Lys. An A-to-G transversion at the third nucleotide of codon 318 was detected in exon 7. B Polymerase chain reaction (PCR)-restriction fragment length polymorphism (RFLP) analysis of exons 5 and 7.

products obtained with primers ex7-2F and ex7-2R and digested with $A v a \mathrm{I}$ produced a 145-bp fragment in the B1 allele that lacked the $A v a \mathrm{I}$ site, and 22-bp and 123-bp fragments in the $\mathrm{B} 2$ allele that retained the recognition sequence. The allelic frequencies of these single-nucleotide polymorphisms (SNPs) were estimated in 122 chromosomes from unrelated Japanese individuals; the results are listed in Table 3.

Chromosomal band 1p36 is frequently involved in nonrandom translocations in hematological malignancies (Mitelman et al. 1997); moreover, loss of heterozygosity $(\mathrm{LOH})$ and chromosomal deletions in this region have been observed in carcinomas arising in a variety of tissues. The $h C A D$ is likely to be a candidate for a tumor suppressor gene. In our additional experiment, allelic imbalances (AI) were observed in only 2 of 31 neuroblastomas, but none of the mutations were detected in any of 7 exons of $h C A D$ in
AluI digestion generated three fragments from exon 5 (99-, 84- and $17-$ bp) from the A1 (AGG) allele, and four fragments (84-, 73-, 26-, and 17-bp) from the A2 (AAG) allele (Arg196Lys) with an additional AluI site. AvaI digestion of the PCR products from exon 7 produced a 145 bp fragment (B1 allele, CCA) lacking the $A v a$ I site, and 22-bp and 123bp fragments from the $\mathrm{B} 2(\mathrm{CCG})$ allele that retained the recognition sequence

Table 3. Allelic frequencies of single nucleotide polymorphism among 61 unrelated human subjects

\begin{tabular}{ccccccc}
\hline \multicolumn{4}{c}{ Genotypes } & & \multicolumn{3}{c}{$\begin{array}{c}\text { Allelic } \\
\text { frequencies }\end{array}$} \\
\hline & $n$ & $\mathrm{~A} 1 / \mathrm{A} 1$ & $\mathrm{~A} 1 / \mathrm{A} 2$ & $\mathrm{~A} 2 / \mathrm{A} 2$ & $\mathrm{~A} 1$ & $\mathrm{~A} 2$ \\
$\mathrm{ex} 5$ & 61 & 40 & 20 & 1 & 0.82 & 0.18 \\
& $n$ & $\mathrm{~B} 1 / \mathrm{B} 1$ & $\mathrm{~B} 1 / \mathrm{B} 2$ & $\mathrm{~B} 2 / \mathrm{B} 2$ & $\mathrm{~B} 1$ & $\mathrm{~B} 2$ \\
$\mathrm{ex} 7$ & 61 & 19 & 27 & 15 & 0.53 & 0.47 \\
\hline
\end{tabular}

these two patients (data not shown). The genomic structure of the $h C A D$ presented here, together with information concerning SNPs within the gene, as well as a highly polymorphic (CT)m(CA)n repeat fragment at the $h C A D$ locus, may assist in the construction of genetic maps for exploring gene(s) that play pivotal roles in carcinogenesis. 
Acknowledgments We are grateful to Dr. Yusuke Nakamura for his continual encouragement. This work is supported by Grants-in-Aid from the Ministry of Health and Welfare of Japan, the Ministry of Education, Science, Sports and Culture of Japan, the Organization for Pharmaceutical Safety and Research (OPSR) of Japan, and in part by the Atsuko Ouchi Memorial Fund.

\section{References}

Enari M, Sakahira H, Yokoyama H, Okawa K, Iwamatsu A, Nagata S (1998) A caspase-activated DNase that degrades DNA during apoptosis, and its inhibitor ICAD. Nature 391:43-50

Gregory SG, Vaudin M, Wooster R, Coleman M, Mischke D, Porter C, Schutte BC, White P, Vance JM (1998) Report of the fourth interna- tional workshop on human chromosome 1 mapping 1998. Cytogenet Cell Genet 83:147-175

Kawane K, Fukuyama H, Adachi M, Sakahira H, Copeland NG, Gilbert DJ, Jenkins NA, Nagata S (1999) Structure and promoter analysis of murine CAD and ICAD genes. Cell Death Diff 6:745-752

Mitelman F, Mertens F, Johaansson B (1997) A breakpoint map of recurrent chromosomal rearrangements in human neoplasia. Nat Genet 15:417-474

Mukae N, Enari M, Sakahira H, Fukuda Y, Inazawa J, Toh H, Nagata S (1998) Molecular cloning and characterization of human caspaseactivated DNase. Proc Natl Acad Sci USA 95:9123-9128

Sakahira H, Enari M, Nagata S (1998) Cleavage of CAD inhibitor in CAD activation and DNA degradation during apoptosis. Nature 391:96-99

White PS, Maris JM, Beltinger C, Sulman E, Marshall HN, Fujimori M, Kaufman BA, Biegel JA, Allen C, Hilliard C (1995) A region of consistent deletion in neuroblastoma maps within human chromosome 1p36.2-36.3. Proc Natl Acad Sci USA 92:5520-5524 